\title{
High Frequency of Skin Reactions in Patients with Leishmaniasis Treated with Meglumine Antimoniate Contaminated with Heavy Metals. A Comparative Approach Using Historical Controls
}

\author{
Gustavo Adolfo Sierra Romero/ ${ }^{+}$, Érico Marlon de Moraes Flores*, Elza Ferreira Noronha, \\ Vanize de Oliveira Macêdo
}

\author{
Núcleo de Medicina Tropical, Universidade de Brasília, Caixa Postal 04517, Campus Universitário, Asa Norte, 70919-970 \\ Brasília DF, Brasil *Departamento de Química, Universidade Federal de Santa Maria, Santa Maria, RS, Brasil
}

\begin{abstract}
We analyzed data from historical controls treated with meglumine antimoniate to compare the frequency of adverse events observed in patients with cutaneous leishmaniasis treated with the same dose of meglumine antimoniate contaminated with heavy metals in an endemic area of the State of Bahia, Brazil. Group A patients were treated in 2000 with the drug produced by Eurofarma Laboratórios Ltda., São Paulo, Brazil (lot A) and group B patients were treated in 1996 with the reference drug produced by Rhodia Farma Ltda., São Paulo, Brazil (lot B). We observed an unusual higher frequency of skin reactions in group A patients. However, all type of adverse events observed in group A were also observed in group B. The physico-chemical analysis of these lots revealed that lot $A$ had lower $p H$ and higher concentration of total and trivalent antimony, lead, cadmium, and arsenic. Our findings suggest that the skin reactions could be attributed to heavy metal contamination of lot A.
\end{abstract}

Key words: pentavalent antimony - heavy metals - cutaneous leishmaniasis - lead - arsenic - toxicity

Pentavalent antimonials had been, for many years, the first-choice drugs for the treatment of leishmaniasis (Marsden 1985, Herwaldt \& Berman 1992, Berman 1997). Two salts are commercially available, meglumine antimoniate and sodium stibogluconate. They are used by the IM or IV route. In Brazil, patients with cutaneous leishmaniasis are treated with meglumine antimoniate, 10$20 \mathrm{mg} / \mathrm{kg} /$ day IM or IV, for 20-30 days following the recommendations of the Brazilian Ministry of Health. The drug usually causes mild to moderate adverse events that rarely lead to treatment suspension. Myalgias, arthralgias, abdominal symptoms, headache, elevation of aminotransferases and amylase, and electrocardiographic changes affecting the ST segment and QTc are the most frequent events (Marsden 1985, Ballow et al. 1987, Franke et al. 1990, Gasser et al. 1994, Berman 1997). Rarely, severe toxicity is observed such as acute renal and hepatic failure (Kopke et al. 1993), thrombocytopenia (Hepburn 1993) and even sudden death, probably due to cardiac rhythm disturbances (Chulay et al. 1985). The presence of trivalent antimony contaminating pentavalent antimonials for clinical use was demonstrated and could explain the toxic events observed during treatment (Franco et al. 1995). Pharmacokinetics of both drugs is comparable and it is assumed that they produce similar therapeutic effects (Chulay et al. 1988). Toxicity caused by antimonials could

This work had financial support of the Conselho Nacional de Desenvolvimento Científico e Tecnológico, Process 420043/012). Drugs were donated by the Fundação Nacional de Saúde. ${ }^{+}$Corresponding author. Fax: +55-61-273.5008. E-mail: gromero@unb.br

Received 2 May 2002

Accepted 5 September 2002 be different for each drug and formal comparisons of sodium stibogluconate and meglumine antimoniate are scarce. We recently compared the efficacy, safety and toxicity of sodium stibogluconate produced in China (sodium stibogluconate BP88® Shandong, Xinhua, China) with meglumine antimoniate (Rhodia Farma, Ltda., São Paulo, Brazil) and our conclusions suggest that sodium stibogluconate was more toxic than the drug produced by Rhodia Farma Ltda. (Saldanha et al. 1999, 2000). There are no definite criteria to evaluate the quality of antimonials. High osmolarity could be a marker of higher toxicity as shown by one report from India (Sundar et al. 1998). We had measured the osmolarity and $\mathrm{pH}$ of different lots of meglumine antimoniate and that physico-chemical properties appear to be stable at least during a three-year period (Romero et al. 1996). The presence of metals such as lead has been reported as a cause of poisoning in patients treated with traditional Chinese remedies (Wu et al. 1996) but there is little information about this kind of contamination in pharmaceutical products (Popinska et al. 1999). Flores et al. (2000) drew attention to the fact that routine quality control of drugs with the appropriate methods to detect heavy metals has been traditionally neglected. Contamination of antimonials with heavy metals such as lead, arsenic and cadmium is not expected unless poor quality control of manufacturing process allows the use of impure salts. We use historical controls (patients with cutaneous leishmaniasis) treated with the unique lot of the reference drug, meglumine antimoniate (Rhodia Farma Ltda., São Paulo, Brazil) in 1996 to compare the frequency of unusual adverse events due to meglumine antimoniate (Eurofarma Laboratórios Ltda., São Paulo, Brazil) used in patients with similar conditions in 2000 . We compared the physico-chemical properties of both drugs raising the hypothesis of toxicity attributed to heavy metal contamination. 


\section{PATIENTS AND METHODS}

Patients - Nineteen patients (Group A) with localized cutaneous leishmaniasis (LCL) were treated with meglumine antimoniate (Eurofarma Laboratorios Ltda., São Paulo, Brazil), $20 \mathrm{mg} / \mathrm{kg} /$ day I. V. for 20 days (Lot A). They were included in a therapeutic protocol aiming the identification of prognostic factors associated with failure to cure from August through December 2000. Lot A was produced for the Brazilian Ministry of Health and correspond to a unique lot No. 011/00 A, valid through May 2002. Patients were provided with disposable syringes and instructed to return every 10 days during treatment and monthly thereafter for a three months period to diagnose failure or cure. Data from group A was compared with data from 54 historical controls (Group B) treated and followed in a similar manner by the same researcher in 1996 with a unique lot of meglumine antimoniate, No. 0595 L061 (Rhodia Farma Ltda, São Paulo, Brazil) (Lot B) in a protocol designed to compare the characteristics of two species of the Viannia subgenus (Romero et al. 2001a, b). Lot B was valid through May 2000. Both groups attended the basic health unit of Corte de Pedra District, Presidente Tancredo Neves municipality, State of Bahia, Brazil, located in an endemic area of Leishmania (Viannia) braziliensis (França et al. 1991). All patients had positive Montenegro skin test performed as recommended by the World Health Organization (WHO 1984) using antigen prepared as described by Reed et al. (1986). All cases had confirmed parasitological diagnosis using the isolation and visualization methods previously described (Romero et al. 2001a). Both research protocols were done in agreement with the Helsinki Declaration and the Resolution 196/96 of the National Health Council of the Ministry of Health of Brazil, which regulates research in humans. The Ethics Research Committee of the University of Brasília approved the protocols. All patients signed informed consents to diagnostic tests and were treated in accordance to the recommendations of the Brazilian Ministry of Health. When the protocol was interrupted because the unusual frequency of adverse events all patients were informed of the potential causes of the phenomenon and instructed to stop medication and report any symptom related to the treatment.

Chemical analysis - All measurements were carried out at the same time in 2001 with an atomic absorption spectrometer Model 3030 B (Perkin Elmer, Germany) equipped with a continuum source background correction system. Equipment was coupled to an electrothermal atomizer (longitudinally heated graphite tube, Model HGA400 , Perkin Elmer) or to a batch hydride generation system (MHS-10, Perkin Elmer). Antimony determinations were performed after water dilution of samples using an air/acetylene flame $(217.6 \mathrm{~nm})$ and pneumatic nebulization. Determinations of arsenic (193.7 nm), cadmium (228.8 $\mathrm{nm})$ and lead $(283.3 \mathrm{~nm})$ were performed by electrothermal atomization using a graphite tube with a specific heating programme (drying, pyrolysis and atomization) for each element. Argon (99.996\%, White-Martins, Brazil) was used as protection gas. Integrated absorbance was used instead of peak height for measurements.
Determination of antimony on the trivalent state in the samples was performed by hydride generation atomic absorption spectrometry using a flame heated quartz cell as atomizer. Samples were diluted with water using $4 \%$ $(\mathrm{m} / \mathrm{v})$ tartaric acid solution as selective medium for trivalent antimony determination. Reductant was a daily prepared $1 \%, \mathrm{~m} / \mathrm{v}$, sodium tetrahydroborate solution. Reference trivalent antimony solutions were daily prepared and absorbance signals were completely recorded in $15 \mathrm{sec}$. Argon was used as purge gas and measurements were made in integrated absorbance mode.

All chemicals used were of analytical reagent grade from Merck (Darmstadt, Germany). Distilled and doubledeionized water (maximum conductivity of $1.2 \mu \mathrm{S} / \mathrm{cm}$ ) was used to prepare all solutions. All glass apparatus were soaked in $0.72 \mathrm{~mol} / \mathrm{l}$ nitric acid, and thoroughly washed with water before use. Working reference solutions were prepared immediately before use by serial dilution from a stock solution containing $1,000 \mathrm{mg} / \mathrm{l}$ for each element. All determinations were made in triplicate from five test samples for each individual lot. $\mathrm{pH}$ was measured with a digital apparatus (Model 10, CELM, Brazil) in 10 ampoules, one measure for each ampoule. The final mean for each lot corresponds to the mean of 10 ampoules.

Osmolarity - This property was measured with a digital Fiske Osmometer (Fiske Associates, Norwood, MA, USA) in 10 ampoules of each lot, obtaining three independent measures for each ampoule for a mean estimate. The mean for each lot was obtained using the mean values of the ten ampoules.

Statistical analysis - The comparisons of the frequency of the observed adverse events were performed with the chi-square test or Fisher exact test and the medians were compared with the Mann-Whitney-U test using the Statistical Package for Social Science, version 9.0, 95\% confidence intervals were calculated using the EPI Info, version 6.04

\section{RESULTS}

Both groups were comparable by age, sex and total body weight. Most patients were agricultural workers. Table I shows the characteristics of the disease and the results of the Montenegro skin test observed in both groups. Table II shows the frequency of adverse events observed in each group. Although the absolute proportion of patients who experiences at least one adverse event was similar between groups, the quality of the observed events was different mainly due to the unusual higher frequency of skin reactions in group A patients. Arthralgias were more frequently observed in group B. The episodes of skin reactions were characterized by the onset of erithematous and itching plaques at the site of the intravenous injections in the forearms and the appearance of generalized morbiliform rash during a secondary stage. Symptoms disappeared 3 to 14 days after the interruption of the medication. Some patients needed antihistaminic medication to improve itching. All patients with skin reactions in group A were instructed to stop treatment. The patient in group $\mathrm{B}$ who experienced a skin reaction had a generalized rash without any plaques on the 19th day of treatment and consulted on the 20th day 
after the administration of the last prescribed dose and her symptoms relief during the next five days. Table III shows the physico-chemical characteristics in the samples of the lots used by each group. Lot A was characterized by lower $\mathrm{pH}$ and osmolarity and higher concentrations of total and trivalent antimony, lead, cadmium and arsenic. The total concentration of antimony was $22 \%$ higher than the expected concentration of $85 \mathrm{mg} / \mathrm{ml}$ indicated by the manufacturer.

TABLE I

Clinical findings observed at entry time in two groups of patients with cutaneous leishmaniasis treated with different lots of meglumine antimoniate in Brazil ${ }^{a}$

\begin{tabular}{|c|c|c|c|}
\hline Clinical finding & $\begin{array}{c}\text { Group A } \\
\mathrm{n}=19\end{array}$ & $\underset{\mathrm{n}=54}{\text { Group } \mathrm{B}^{c}}$ & $\begin{array}{r}\text { Statistical } \\
\text { significance }\end{array}$ \\
\hline $\begin{array}{l}\text { Age-years } \\
\text { (median) }\end{array}$ & $\begin{array}{c}21.5 \\
(14.0-32)\end{array}$ & $\begin{array}{c}22.0 \\
(17.0-31.0)\end{array}$ & 0.505 \\
\hline Sex (male) & $10 / 19(52.6)$ & $40 / 54(74.1)$ & 0.084 \\
\hline $\begin{array}{l}\text { Number of lesions } \\
\text { (median) }\end{array}$ & $\begin{array}{c}1 \\
(1-2)\end{array}$ & $\begin{array}{c}1 \\
(1-2)\end{array}$ & 0.840 \\
\hline $\begin{array}{l}\text { Total body weight }-\mathrm{kg} \\
\text { (median) }\end{array}$ & $\begin{array}{c}50.0 \\
(45.0-59.0)\end{array}$ & $\begin{array}{c}52.0 \\
(42.8-60.3)\end{array}$ & 0.816 \\
\hline $\begin{array}{l}\text { Total ulcerated } \\
\text { area- } \mathrm{cm}^{2} \text { (median) }\end{array}$ & $\begin{array}{c}2.33 \\
(1.22-5.42)\end{array}$ & $\begin{array}{c}1.37 \\
(1.02-2.86)\end{array}$ & 0.152 \\
\hline $\begin{array}{l}\text { Disease duration- } \\
\text { weeks (median) }\end{array}$ & $\begin{array}{c}4.0 \\
(3.0-6.0)\end{array}$ & $\begin{array}{c}4.0 \\
(2.0-12.0)\end{array}$ & 0.458 \\
\hline $\begin{array}{l}\text { Montenegro skin } \\
\text { test-mm (median) }\end{array}$ & $\begin{array}{c}16.0 \\
(14.0-20.2)\end{array}$ & $\begin{array}{c}18.0 \\
(14.0-2.0)\end{array}$ & 0.549 \\
\hline
\end{tabular}

$a$ : numbers in parenthesis are $25-75$ quartiles for medians and $\%$ for proportions; $b$ : group A received meglumine antimoniate, lot 011/00 A (Eurofarma Laboratórios, Ltda., São Paulo, Brazil); c: group B received meglumine antimoniate, lot 0595L061, (Rhodia Farma, São Paulo, Brazil); $d$ : statistical significance corresponds to Mann-Whitney U test except for the proportion of male sex comparison that was performed using Chi square test

TABLE II

Comparison of adverse events observed in two groups of patients with cutaneous leishmaniasis treated with different lots of meglumine antimoniate in Brazil

\begin{tabular}{|c|c|c|c|}
\hline Adverse event & $\begin{array}{l}\text { Group A } \\
\mathrm{n}=19(\%)\end{array}$ & $\begin{array}{l}\text { Group B } \\
\mathrm{n}=54(\%)\end{array}$ & $\begin{array}{c}\text { Statistical } \\
\text { significance }^{c}\end{array}$ \\
\hline Mylagias & $5(26.3)$ & $13(24.1)$ & 1.000 \\
\hline Arthralgias & $2(10.5)$ & $19(35.2)$ & 0.045 \\
\hline Anorexia & $2(10.5)$ & $14(25.9)$ & 0.210 \\
\hline Headache & $2(10.5)$ & $11(20.4)$ & 0.492 \\
\hline Fever & $3(15.8)$ & $16(29.6)$ & 0.363 \\
\hline Rash & $7(36.8)$ & $1(1.9)$ & $<0.001$ \\
\hline Fatigue & $2(10.5)$ & $2(3.7)$ & 0.276 \\
\hline Stop work ${ }^{d}$ & $2(10.5)$ & $4(7.4)$ & 0.647 \\
\hline Any adverse event & $14(73.7)$ & $36(66.7)$ & 0.571 \\
\hline
\end{tabular}

$a$ : group A received meglumine antimoniate, lot 011/00 A (Eurofarma Laboratórios, Ltda., São Paulo, Brazil); $b$ : group B received meglumine antimoniate, lot 0595L061 (Rhodia Farma, São Paulo, Brazil); $c$ : statistical significance corresponds to Fisher exact test except for comparisons of the categories: arthralgias and any adverse event that were performed with the Chi square test; $d$ : proportion of individuals who stopped normal activities

\section{TABLE III}

Physico-chemical characteristics of two lots of meglumine antimoniate used for treatment of patients with cutaneous leishmaniasis in Brazil ${ }^{a}$

\begin{tabular}{lcc}
\hline Characteristic & Lot $^{b}$ & Lot B $^{c}$ \\
\hline PH & $4.5(0.05)$ & $6.7(0.05)$ \\
& {$[4.48-4.56]$} & {$[6.78-6.83]$} \\
Osmolarity (mosm/l) & $708.9(5.86)$ & $959.3(22.44)$ \\
& {$[704.7-713.1]$} & {$[952.5-965.7]$} \\
Total antimony $\left(\mathrm{Sb}^{\mathrm{III}}+\mathrm{Sb}^{\mathrm{V}}\right)$ & $103.9(1.4)$ & $88.1(1.2)$ \\
$(\mathrm{mg} / \mathrm{ml})$ & & \\
Trivalent antimony $(\mathrm{mg} / \mathrm{ml})$ & $3.45(0.31)$ & $1.82(0.25)$ \\
Heavy metals & & \\
Lead (mg/l) & $52.71(1.29)$ & $<0.20$ \\
Arsenic (mg/l) & $35.79(1.54)$ & $<0.90$ \\
Cadmium (mg/l) & $0.132(0.014)$ & $<0.04$ \\
\hline
\end{tabular}

$a$ : numbers in parenthesis correspond to SD. Numbers in brackets correspond to $95 \% \mathrm{CI} ; b$ : meglumine antimoniate, lot 011/00 A (Eurofarma Laboratórios, Ltda., São Paulo, Brazil); c: meglumine antimoniate, lot 0595L061 (Rhodia Farma, Ltda., São Paulo, Brazil)

\section{DISCUSSION}

Our data showed that the frequency of skin reaction, an unusual adverse event, was higher in patients treated with the drug containing a high concentration of lead, cadmium and arsenic. Although historical controls had limitations for comparisons in our case the therapeutic protocols were identical and the same researcher was responsible for the adverse events monitoring and followup. Furthermore the chemical analysis was performed at the same time to avoid variations in the assay sensitivity. We storage samples of the lot B used to treat the historical controls avoiding exposure to light at room temperatures. We do not perform biochemical and electrocardiographic tests to identify other kind of effects such as cardiac, hepatic and pancreatic toxicity but it would be expected a higher level of cardiac abnormalities since patients received also a higher dose of total and trivalent antimony that have shown a dose dependent toxicity on the heart (Chulay et al. 1985). The type of the skin reactions observed in group A patients could be attributed initially to local sensitization with contaminant heavy metals with posterior generalized rash. Arsenic, lead and cadmium have been described as causes of contact allergy (Cavelier \& Foussereau 1995). Pentavalent antimony could cause generalized rash but the phenomenon is rare even with prolonged courses of the maximum recommended dose (Franke et al. 1994). In our case it appears to be more plausible the hypothesis of reactions due to arsenic, lead or cadmium. The concentration of total and trivalent antimony was higher in lot A. The trivalent species is considered more toxic and more active than the pentavalent form but patients usually tolerate high antimony doses and rarely develop skin reactions.

Mean osmolarity levels in both lots was in the expected range of values based in our experience measur- 
ing osmolarity of at least ten different lots of meglumine antimoniate. Lower $\mathrm{pH}$ could explain in part the local skin reactions at the injection site but do not explain the systemic toxicity manifested as generalized rash.

Our results together with the reported analysis of the reactions observed with other two lots of the drug produced by Eurofarma Laboratórios Ltda., São Paulo, Brazil confirming heavy metal contamination (Brazilian Ministry of Health 2001), indicates that the unusual frequency of cutaneous reactions observed in group A patients could be attributed to heavy metal contamination.

The use of drug salts from dubious origin could explain the contamination with heavy metals despite good manufacturing practices during the dilution process. Our data raise the urgent need to establish stringent criteria for quality control of pentavalent antimonials including the inspection of sources of chemical supplies. Recent report of successful treatment of visceral leishmaniasis in Kenya using a cheaper generic sodium stibogluconate produced following good manufacturing practices shows that the production of generic drugs of adequate quality could be an achievable goal (Moore et al. 2001). However the unexpected high frequency of rash episodes observed in both intervention groups in that research deserves more attention to identify the causes of that phenomenon. Pentavalent antimonial characteristics are the antithesis of the ideal drug profile for the treatment of any disease, the situation is the worst possible if we consider that leishmaniasis affects mainly poor people living in less developed countries where health services usually show precarious conditions. Until the development of cheaper oral medications with minor toxicity, the important next step should be the construction of a surveillance system for adverse events observed with pentavalent antimonials aiming the early detection of the more dangerous forms of toxicity to avoid potentially lethal outcomes.

\section{REFERENCES}

Ballou WR, Mc Cain JB, Gordon DM Shanks GD, Andujar J, Berman JD, Chulay JD 1987. Safety and efficacy of highdose sodium stibogluconate therapy of American cutaneous leishmaniasis. Lancet ii: 13-16.

Berman JD 1997. Human leishmaniasis: clinical, diagnostic, and chemotherapeutic developments in the last 10 years. Clin Infect Dis 24: 684-703.

Brazilian Ministry of Health 2001. Antimoniato de meglumina. Rev Soc Bras Med Trop 34: 103-105.

Cavelier C, Foussereau J 1995. Contact allergy to metals and their salts. 3. Other metals. Derm Beruf Umwelt 43: 202-209.

Chulay JD, Fleckenstein L, Smith AH 1988. Pharmacokinetics of antimony during treatment of visceral leishmamiasis with sodium stibogluconate or meglumine antimoniate. Trans $R$ Soc Trop Med Hyg 82: 69-72.

Chulay JD, Spencer HC, Mugambi M 1985. Electrocardiographic changes during treatment of leishmaniasis with pentavalent antimony (sodium stibogluconate). Am J Trop Med Hyg 34: 702-709.

Flores EMM, Bittencourt CF, Laporta LV, Barin JS 2000. Controle de metais pesados em produtos farmacêuticos: aspectos analíticos relevantes. Pharm Technol 4: 9-13.

Franco MA, Barbosa AC, Rath S, Dorea JG 1995. Antimony oxidation states in antileishmanial drugs. Am J Trop Med
Hyg 52: 435-437.

França F, Lago EL, Tada S, Costa JML, Vale K, Oliveira J, Costa MA, Osaki M, Cheever L, Netto EM, Barreto AC, Johnson WD, Marsden PD 1991. An outbreak of human Leishmania (Viannia) braziliensis infection. Mem Inst Oswaldo Cruz 86: 169-174.

Franke ED, Llanos-Cuentas A, Echevarria JE, Cruz MF, Campos P, Tovar AA, Lucas CM, Berman JD 1994. Efficacy of 28-day and 40-day regimens of sodium stibogluconate (Pentostam) in the treatment of mucosal leishmaniasis. Am J Trop Med Hyg 51: 77-82.

Franke ED, Wignall FS, Cruz ME, Rosales E, Tovar AA, Lucas CM, Llanos-Cuentas A, Berman JD 1990. Efficacy and toxicity of sodium stibogluconate for mucosal leishmaniasis. Ann Intern Med 113: 934-940.

Gasser Jr RA, Magill AJ, Oster CN, Franke ED, Grogl M, Berman JD 1994. Pancreatitis induced by pentavalent antimonial agents during treatment of leishmaniasis. Clin Infect Dis 18: 83-90.

Hepburn NC 1993. Thrombocytopenia complicating sodium stibogluconate therapy for cutaneous leishmaniasis. Trans $R$ Soc Trop Med Hyg 87: 691.

Herwaldt BL, Berman JD 1992. Recommendations for treating leishmaniasis with sodium stibogluconate (Pentostam) and review of pertinent clinical studies. Am J Trop Med Hyg 46: 296-306.

Kopke LFF, Café MSM, Neves LB, Scherrer MAR, MachadoPinto J, Souza MSLA, Vale ES, Andrade ARC, Figueiredo JOP, Silva RANP 1993. Morte após uso de antimonial pentavalente em leishmaniose tegumentar americana. An Bras Dermatol 68: 259-261.

Marsden PD 1985. Pentavalent antimonials: old drugs for new diseases. Rev Soc Bras Med Trop 18: 187-198.

Moore E, O’ Flaherty D, Heuvelmans H, Seaman J, Veeken H, Wit S, Davidson R 2001. Comparison of generic and proprietary sodium stibogluconate for the treatment of visceral leishmaniasis in Kenya. Bull WHO 79: 388-392.

Popinska K, Kierkus J, Lyszkowska M, Socha J, Pietraszek E, Kmiotek W, Ksiazyk J. 1999. Aluminum contamination of parenteral nutrition additives, amino acid solutions and lipid emulsions. Nutrition 15: 683-686.

Reed SG, Badaró R, Masur H, Carvalho EM, Lorenço R, Lisboa A, Teixeira R, Johnson WD, Jones TC 1986. Selection of a specific skin test antigen for American visceral leishmaniasis. Am J Trop Med Hyg 35: 78-85.

Romero GAS, Guerra MVF, Paes MG, Macêdo VO 2001a. Comparison of cutaneous leishmaniasis due to Leishmania (Viannia) braziliensis and L. (V.) guyanensis in Brazil: clinical findings and diagnostic appprach. Clin Infect Dis 32: 1304-1312.

Romero GAS, Guerra MVF, Paes MG, Macêdo VO 2001b. Comparison of cutaneous leishmaniasis due to Leishmania (Viannia) braziliensis and L.(V.) guyanensis in Brazil: therapeutic response to meglumine antimoniate. Am J Trop Med Hyg 65: 456-465.

Romero GAS, Oliveira MRF, Correia-Filho D, Marsden PD 1996. Características físico-químicas do antimoniato de meglumina em diferentes condições de armazenamento. Rev Soc Bras Med Trop 29: 461-465.

Saldanha ACR, Romero GAS, Guerra C, Merchan-Hamann E, MacêdoVO 2000. Estudo comparativo entre estibogluconato de sódio $\mathrm{BP} 88^{\mathrm{R}}$ e antimoniato de meglumina no tratamento da leishmaniose cutânea II. Toxicidade bioquímica e cardíaca. Rev Soc Bras Med Trop 33: 383-388.

Saldanha ACR, Romero GAS, Merchan-Hamann E, Magalhães 
AV, Macêdo VO 1999. Estudo comparativo entre estibogluconato de sódio BP $88^{\mathrm{R}}$ e antimoniato de meglumina no tratamento da leishmaniose cutânea: I. Eficácia e segurança. Rev Soc Bras Med Trop 32: 383-387.

Sundar S, Sinha PR, Agrawal NK, Srivastava R, Rainey P, Berman JD, Murray HW, Singh VP 1998. A cluster of cases of severe cardiotoxicity among Kala-azar patients treated with a hihg-osmolarity lot of sodium antimony gluconate.
Am J Trop Med Hyg 59: 139-143.

WHO-World Health Organization 1984. The Leishmaniasis, Report of a WHO Expert Committee, Tech Rep Ser 701, Geneve.

Wu TN, Yang KC, Wang CM, Lai JS, Ko KN, Chang PY, Liou SH 1996. Lead poisoning caused by contaminated Cordyceps, a Chinese herbal medicine: two case reports. Sci Total Environ 182: 193-195. 
150 Antimonial Contaminated with Heavy Metals - Gustavo Adolfo Sierra Romero et al. 